\title{
Teaching through the screen voices of tertiary PE teachers during pandemic
}

\author{
Belleza, Saramie $\measuredangle$ \\ University of Mindanao Tagum College, Philippines (bellezasaramie@yahoo.com) \\ Ronamo, Charity \\ Cotabato Foundation College of Science and Technology, Philippines (charityronamo@gmail.com) \\ Vestil, Catherine \\ Cebu Doctors'University, Philippines (cathy.vestil@gmail.com) \\ Ompoc, Ronald \\ Nasipit Central Elementary School, Philippines (ronaldompoc1983@gmail.com)
}

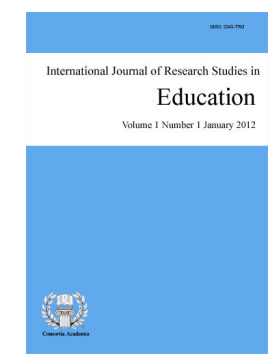

ISSN: 2243-7703 Online ISSN: 2243-7711

OPEN ACCESS

Received: 10 January $2022 \quad$ Revised: 19 January $2022 \quad$ Accepted: 23 January 2022 Available Online: 23 January $2022 \quad$ DOI: $10.5861 /$ ijrse.2022.107

\section{Abstract}

The Physical Education teachers have trouble with online classes. It is slower to communicate and it's harder to keep track of students' exercise through a computer screen. Some teachers have issues providing feedback when they can't see the progress made in their students. Teachers have a very limited number of activities and exercises to assign to students because not all students have the equipment needed. This study explores the experiences and challenges encountered by the tertiary Physical Education teachers in online teaching in times of COVID-19 pandemic in UM Tagum College, Cebu Doctors' University and the Cotabato Foundation College of Science and Technology. Six college physical education teachers participated in this study. A qualitative case study method employing phenomenological procedures to collect and analyzed the data was used. The challenges encountered by the Physical Education teachers in online teaching includes slow internet connection, outdated device and software, late submission of students' output, difficulty in assessing performance task, difficulty in demonstration of skills and health issues. Meanwhile, the coping up mechanisms of Physical Education teachers on the challenges encountered involves the use messaging apps which use least amount of data, giving considerations to students, peer tutoring, prerecorded assessment, make a prerecorded video demonstration, and adapting the situation. This study showed that indeed every narrative account of the informant is a text to be read which attempted to determine the multiple concerns of their experiences in the implementation of the new normal education in times of COVID-19 pandemic that remains to be encouraging and exhilarating. Future studies should establish a theoretical framework for online physical education classes by examining the educational value of modifying existing pedagogical methods, content, evaluations, and so on to teach online Physical Education classes more effectively.

Keywords: Corona Virus disease-19 pandemic; online learning; physical education teachers; experiences 


\section{Teaching through the screen voices of tertiary PE teachers during pandemic}

\section{Introduction}

The entire world is facing a catastrophic situation resulting from the Coronavirus Disease 2019 (COVID-19) pandemic, which has affected the daily lives of people worldwide. Since the World Health Organization declared a pandemic on 11 March 2020, avoiding face-to-face activities and engaging in social distancing have become a part of everyday life. The COVID-19 pandemic has affected educational systems worldwide, leading to the closures of schools, universities and colleges. After the DOH reported the first COVID-19 case in the country, acquired through local transmission, the Philippine President Rodrigo R. Duterte signed Proclamation No. 922 on 8 March 2020, declaring the country under a state of public health emergency. This was to prevent the further spread of the disease and mitigate its effects on communities.

It is very clear that PE teachers cannot deny that they are struggling to teach their students in the midst of a pandemic. These problems stem from a lack of technological resources, educational pedagogy and even physical, mental, and socio-economic issues affecting the teaching-learning process. Since no other study has been done on the problems that Physical Education faces in State Colleges and Universities, the findings can be seen as a foundation for future research and to help revitalize physical education classes. Thus, this study was conceptualized to identify challenges encountered by teachers in conducting online PE classes, and how to cope with these challenges.

\subsection{Purpose of the Study}

The main purpose of the study is to explore the experiences and challenges encountered by the Physical Education teachers in times of COVID-19 pandemic in tertiary level in during the second semester academic year 2020-2021. Specifically, the study sought to answer the following queries:

$>$ What are the challenges encountered by Physical Education teachers on online teaching in Physical Education in times of COVID-19 pandemic?

$>$ How do Physical Education teachers cope up with the challenges?

\section{Method}

The study employed a qualitative case study method using phenomenological procedures to collect and analyze the data. "Turning to the nature of lived experience" of research participants' online physical education classes, the study explored the experience of conducting these classes, discussed and reflected on their efficient operation and difficulties experienced therein, and examined the data by "writing and rewriting". According to Creswell (2007), a phenomenological study "describes the meaning for several individuals of their lived experiences of a concept or a phenomenon" In other words, it focuses on describing a phenomenon that all the participants have experienced, such as the experiences of PE Teachers' experiences in teaching PE during the COVID 19 Pandemic.

\subsection{Participants}

The participants of this study were the PE teachers from the tertiary level particularly from UM Tagum College, Cebu Doctors' University and Cotabato Foundation College of Science and Technology. Participants were purposively selected for this study. Raagas (2010) suggested that a purpose sampling of five to twenty individuals would be used in the phenomenological study. The selection of 6 teachers teaching Physical Education subjects in the tertiary level in an online setting served as the participants. The participants communicated and elaborated this phenomenon daily (Moscovici, 1988) as part of their undertakings. These

38 Consortia Academia Publishing (A partner of Network of Professional Researchers and Educators) 
Teaching through the screen voices of tertiary PE teachers during pandemic

teachers were chosen as participants on the confidence and trust that they can give helpful information that this study required.

\subsection{Data Analysis}

This study used Thematic analysis in analyzing the data. Thematic Analysis is a method of analyzing qualitative data. It is usually applied to a set of texts; such as interview transcripts. The researchers closely examine the data to identify common themes - topics, ideas and patterns of meaning that come up repeatedly. This process was originally developed for psychology research by Virginia Braun and Victoria Clarke. However, thematic analysis is a flexible method that can be adapted to many different kinds of research.

\section{Results and Discussion}

\subsection{Themes on the experiences of PE teachers}

Theme 1.1 Slow Internet Connection - Access to the Internet has become a sore spot for the Philippines lately. Now that people are working from home, most are finding that their personal providers are slow, unreliable, or, worst, unavailable, as in there is no connection to the world wide web at all.

"We have lots of problems we encountered in conducting online classes, number one is the unstable internet connection. Since we are using online platforms such as Google Classroom, Zoom, Shared Drives, and others, strong internet connection is really necessary.” (Participant 002).

Slow Internet connections or limited access from homes in rural areas can contribute to students falling behind academically. The educational setbacks can have significant impacts on academic success, college admissions and career opportunities.

Theme 1.2 Outdated Device and Software - Not all students or teachers use a computer at home, are frequent users, have sufficient data or internet access. There is a digital divide of reduced computer literacy in students from Indigenous, lower socioeconomic or regional/rural backgrounds.

“Another problem I have encountered is the incompatibility of students' devices. Sometimes, the file can't be opened in the learners' end because the version of their devices are outdated (Participant 006)

This creates challenges for teachers if they have to set different tasks for different students, or if they avoid setting homework with a digital component. Lack of technology in the classroom hinders literacy and work-readiness. A new teacher survey has shown that teachers believe technology can boost pupils' literacy, but poor access to resources and outdated device means many are missing out.

Theme 1.3 Late Submission of Students Outputs - From the childhood days, the DIN (Do It Now) concept has been dinned into us - that we should finish our tasks at the earliest, if not immediately. As a student, assignment submission is an important and recurring task. The topmost priority for any student is to stay up to date with their studies and assignments. Failing to submit work by the allotted time is a constant dread during the academic years. While students try their best to keep up with their studies, sometimes certain unfortunate occurrences can force them to go off-track due to poor internet connectivity.

"Students cannot pass their outputs in a scheduled time" (Participant 003)

"Another one is the gadget and the form of technology they are using. They have like low quality of cell phones, they don't have super high-end phones and of course the time that they are requiring for them to submit the needed requirements and they don't really so much time to 
submit and lastly of course they have always reasoning out that they have to go to internet shop to a place that have internet connection." (Participant 006)

From Managing your time to meet deadlines is an important part of the assessment process. Failure to meet deadlines without acceptable extenuating circumstances will automatically result in the deduction of marks and the same approach is used across the institution of higher learning.

This implies that teacher's policy on submission of students' output is not the sole basis of authentic students' academic performance. Teachers should evaluate the reasons why some of the students submit after the deadline set by the teacher.

Theme 1. 4 Difficulty in Assessing Performance Task - A performance task is any learning activity or assessment that asks students to perform to demonstrate their knowledge, understanding and proficiency. Performance tasks yield a tangible product and/or performance that serve as evidence of learning. Online physical education performance is difficult to evaluate.

"Giving specific assessments without our presence is complicated, because students may encounter difficulties in performing such activity or students may have got injured during the demonstration of the performance task". (Participant 005).

This matter entails that teacher should have to find ways in assessing the student's performances in formative or summative assessment. Similarly known as assessment for learning, formative assessment requires teachers to frequently assess students' academic progress in order to identify their learning needs and to inform the next phase of teaching and learning.

Theme 1. 5 Difficulty in Demonstration of Skills - The use of demonstrations is one of numerous pedagogical interventions that have been adopted for enhancing students' interest. Skill demonstration activities are really helpful for a learner to analyze the skills that he has learnt. It is important to know what you are getting into and how you can effectively prepare for the lesson.

"The shift of online teaching is difficult especially for us physical education teachers specifically on the demonstration of skills. Demonstration is limited due to some reasons like internet connection, limited equipment, and of course facilities". (Participant 006)

This implies that based on the informants of this study, they really have to look into strategies that will address this particular problem and to improve teaching styles. Educators must spend a lot of time in making effective strategies in online teaching. Pedagogical and technical competency of online educators is of utmost importance.

Theme 1. 6 Health Issues - Moving learning from classrooms to homes at scale and in a timely manner poses enormous human physical challenges (for example, establishing, sustaining, and enhancing distance learning, or assessing and validating learning) (UNESCO, 2020).

"Most of my time is spent facing my laptop and cellphones answering the queries of my students,

I am just concern with my health because of too much radiation." (Participant 001)

Spending more time on the internet puts our physical health at risk, leading to a move away from healthy leisure pursuits and recreational sports and toward sedentary entertainment like television, video games, and computers. (University of Minnesota, 2007; Wang et al., 2012). This sedentary behavior is associated with many health risks such as cardiovascular disease, the leading causes of death in the United States.

Similarly, the importance of physical activity in the general health and wellbeing of teachers during lockdown should be considered, as research has shown that teachers who exercise more during their free time or in a more independent manner have less physical and mental health issues (Bogaert et al., 2014). 


\subsection{Themes on coping strategies of PE teachers}

Theme 2.1 Use messaging apps which use least amount of data - Users are more and more often looking for messaging apps that use little data for calling and texting. Low data usage is especially important in those countries where the internet is limited. Also, it's important in those places where the internet speed is slow, or the internet accessibility is low.

"For the students who cannot access to the google classroom, I allowed them to submit in my FB Messenger personal account because FB Messenger is free” (Participant 003)

Whether you're answering a question, troubleshooting a problem, or sharing information, it can be helpful to send images or other files back and forth. Technical issues can often be resolved quite easily using screenshot. There is definitely a reason why a picture is worth more than a thousand words. With Facebook Messenger, you can send images and files as much as you want, and your students can do the same. It's the perfect communication tool.

Theme 2.2 Giving Considerations to Students by Providing More Examples Like Video Presentation Studies have shown that the use of short video clips allows for more efficient processing and memory recall. The visual and auditory nature of videos appeals to a wide audience and allows each user to process information in a way that's natural to them. This implies that majority of my students have a better memory for images than words. A visual learner learns by reading or seeing pictures. Understands and remembers things by sight.

"In handling these problems, we should be patiently enough so that I gave enough time to my students to answer the assessment task. I provided videos for my students to benchmark the proper executions in practical and performance task”. (Participant 004)

When we are considerate of our students, it makes them feel loved and respected. It makes the world a better place to live in. As much as people value honesty, they also value someone who respects their feelings. It is okay to speak the truth, but don't tear apart a person's self-esteem. Studies have shown that the use of short video clips allows for more efficient processing and memory recall. The visual and auditory nature of videos appeals to a wide audience and allows each user to process information in a way that's natural to them.

Theme 2.3 Peer Tutoring - Peer tutoring is generally accepted as a strongly research-based, and increasingly popular, teaching technique that has positive impact on students. While the structure of peer tutoring can take many forms, generally the teacher provides the new content of a lesson and then structures the class so that students can drill the information in small groups.

"We are doing alternatives. One student who have better connection will download the modules or activity and he or she will share the files to his or her classmates that lives nearby. Also, I am giving extensions to the students as long as the time frame given is reasonable”. (Participant 002)

Peer tutoring technique is an effective way for students to teach and practice what they have learned to solidify their understanding, while gaining more one-on-one discussion and attention. Additionally, this instructional practice provides an opportunity for positive social interactions and content mastery. This implies that peer tutoring enables both tutor and tutee to gain self-confidence, the tutor by observing self-competence in his or her capability to help someone. Peer tutoring allows for higher rates of student response and feedback, which results in better academic achievement. It also creates more opportunities for students to practice specific skills, which leads to better retention.

Theme 2.4 Pre-Recorded Assessment - Student assessment provides accountability for standards-based learning and is a key component of the education process in all subject areas. Digital recordings can be an efficient method of providing feedback comments to students; however, the vast majority of empirical studies 
have focused on tertiary contexts.

Basically, in physical education subject majority of our assessment is performance based, so I told them to use phones, tablet or laptops to record their output”. (Participant 001)

Learning has been the subject of the technical initiatives with the number of targets for quite some time. In the academic sense, the term technical interference or advancement may refer to various applications of electronic gadgets with emphasis put on the student or the learning experience. (Kirkwood \& Price, 2013).

This denotes that, the teachers should be innovative and creative when assessing student's performances. There must be a realistic suggestion to the teachers to improve and develop a good assessment in online teaching. Teachers need to take an active role in making decisions about the purpose of assessment and the content that is being assessed.

Theme 2.5 Make a Pre-recorded video demonstration - Video provides great benefits to teachers and learners, stimulating stronger course performance in many contexts, and affecting student motivations, confidence and attitudes positively.

"Lagging during live demonstration, so instead of performing live, I opt to record my skill demonstration”. (Participant 004).

The influence of digital videos on our everyday culture is undeniable. The use of videos in teaching and learning serves to not only benefit students, but also teachers. Indeed, many teachers are choosing to create their own recorded skill demonstration as learning materials. Video provides great benefits to teachers and learners, stimulating stronger course performance in many contexts, and affecting student motivations, confidence and attitudes positively.

This matter entails that teacher should be creative, resourceful, and innovative with the teaching strategies that he or she is applying. Having a high-quality faculty is important for online education to be effective. Professional learning should emphasize how to successfully facilitate the class and adapt instruction of teachers to adjust to the online environment. Video is being used in a variety of ways to support various pedagogical strategies successfully.

Theme 2.6 Adapting the Situation - As a result of COVID-19, school districts are now looking for an online platform that can be used by both teachers and students to help them excel. Unfortunately, moving to online learning after decades of dismissal is not as easy as one would expect. A lot more planning and preparation is required than in a typical face-to face course. (Baran et al., 2013).

"I just live with it - I have no choice but to ADOPT AND ADAPT. I just want my students to learn and pass the course despite the pandemic; I have to accept it, even though it hurts me." (Participant 001)

According to the findings, although the majority of Physical Education teachers face challenges in adapting to online learning, adaptation is an important strategy in educational settings because it enhances relationships among students, teachers, and institutions. This will improve educational opportunities for teachers who are juggling school, job, and family commitments, as well as other issues.

\section{Conclusion}

The study concludes that physical education classes are fraught with difficulty during a pandemic. This state of lockdown has created significant problems in the lives of teachers, as evidenced by the pressure that online educational methods have put on them. Indeed, due to their diverse experiences, the participants provided very rich information that provided answers to the research questions examined. The results of this phenomenological study identified a variety of challenges that affect the quality of teaching by teachers and the achievement of

42 Consortia Academia Publishing (A partner of Network of Professional Researchers and Educators) 
Teaching through the screen voices of tertiary PE teachers during pandemic

student learning outcomes. The individual must make a conscious effort and devote time to tasks and activities in order to complete the necessary tasks and activities. Teachers need to provide more lesson plans and various learning tools to adequately meet the needs and demands of their students. Along with these obstacles, a solution needs to be developed for teaching methods, technical willingness to incorporate online learning, and support and encouragement from all involved. Education must be seen as a collaborative community effort involving government, teachers, parents and schools to improve the effectiveness of teaching and learning methods that have been harmed and to ensure that students are not left behind.

\subsection{Implication}

This study implies that this situation of lockdown has led to major problems in teachers' lives, as evidenced by the pressure that online educational methods have placed on them: many hours of work and difficulties due to the lack of physical contact or due to the obstacles created on combining personal life with family.This study showed that indeed every narrative account of the informant is a text to be read which attempted to determine the multiple concerns of their experiences in the implementation of the new normal education in times of COVID-19 pandemic that remains to be encouraging and exhilarating.

\section{References}

Blaine, A. M. (2022) Interaction and presence in the virtual classroom: An analysis of the perceptions of students and teachers in online and blended advanced placement courses. Computers and Education, 132, 31-43.

Buschner, C. (2006). Online physical education: Wires and lights in a box. The Journal of Physical Education, Recreation and Dance, 77, 3-5.

Goodway, J. D., Crowe, H., \& Ward, P. (2003). Effects of motors kill instruction on fundamental motor skill development. Adapted Physical Activity Quarterly, 20, 298-314.

Hong, S. H. (2006). A study on teaching and learning plan of physical education in middle school using blended learning strategy linked. Korean Journal of Physical Education, 45, 387-402.

Jeong, H.-C., \& So, W.-Y. (2020). Difficulties of online physical education classes in middle and high school and an efficient operation plan to address them. Int. J. Environ. Res. Public Health, 17, 7279. https://doi.org/10.3390/ijerph17197279

Lee, E. J. (2006). A study on college students' perception on convenience in online courses. J. Educ. Inf. Media, $16,341-362$.

Strauss, A. \& Corbin, J. (1998). Basics of qualitative research: Grounded theory procedures and techniques (2nd ed.). Thousand Oaks, CA: Sage. 
Belleza, S., Ronamo, C., Vestil, C., \& Ompoc, R.

44 Consortia Academia Publishing (A partner of Network of Professional Researchers and Educators) 